because there is less energy released in the formation of these fragments than in the formation of fragments with atomic numbers in the range shown. In addition, Fig. 1 gives a qualitative indication that the highest release of energy would occur in fission when nuclides are formed which are equally deficient in neutrons, and this is in accordance with the equal-charge displacement hypothesis for the distribution of charge in fission ${ }^{6}$.

\section{G. N. Walton}

Chemistry Division,

Atomic Energy Research Establishment, Harwell.

${ }^{1}$ Katcoff, S., Miskel, J. A., and Stanley, C. W., Phys. Rev., 74, 631 (1948).

${ }^{2}$ Gibson, W. M., Thomas, T. D., and Miller, G. L., Phys. Rev. Letters, 7 , 65 (1961). Milton, J. C. D., and Fraser, J. S., Phys. Rev. Letters, 7,67 (1961).

${ }^{8}$ Stein, W. E., and Whetstone, jun., S. L., Phys. Rev., 110, 476 (1958). Fraser, J. S., and Milton, J. C. D, ibid, 93,818 (1954). Milton J. C. D., and Fraser, J. S., ibid., il1, 877 (1958).

4 Fong, P., Phys. Rev., 102, 434 (1956). Newton, T. D., A tomic Energy of Canada, Ltd., Report CRL-642-A (1956). Cameron, A. G. W. Second Qeneva COnf. on Peacefal Dses of Atomic Energy, 15, 42 (1958).

'Koenig, L. A., Mattauch, J. H. E., and Wapstra, A. H., 1960 Nuclear Data Tables, Part 2 (Nat. Acad. Sci., Washington, D.C.).

-Glendenin, L. E., Coryell, C. D., and Edwards, R. R., N.N.E.S. The Fission Products Paper 52 (McGraw-Hill, 1951).

\section{ENGINEERING}

\section{Non-Linear Transmission Lines for Millimetre Wave Generation and Recep- tion}

THE properties of non-linear transmission lines, containing, for example, ferroelectric material of the barium titanate class, have been examined in connexion with a computing system ${ }^{1}$. Their possible use as a variable capacity parametric amplifier element is obvious, and it has been shown recently that an electromagnetic shock-wave can be propagated ${ }^{2}$. This effect occurs when a signal of large amplitude is injected into the line. The high-field part of the wave travels at a greater speed than the low-field part so that a sine wave becomes a saw-tooth. After a certain time this has a vertical leading edge analogous to a shock-wave in a gas. Such a wave is rich in harmonics and a number of lines, driven with power derived from the same microwave magnetron and with outputs recombined through phase shifters, could be an efficient harmonic generator.

A less obvious method of generating higher frequencies with a non-linear line is as follows: Suppose a low-level microwave signal is fed into a wave-guide filled with ferroelectric, and that this guide is constructed so that it is possible to apply a d.c. bias voltage to change the permittivity of the dielectric. Suppose the signal pulse duration is for a certain time and that during this time the bias is changed so that the velocity of wave propagation increases. The emergent signal will then occupy a shorter time, but as it contains an unchanged number of oscillations the frequency will be increased. Also as energy is conserved the power will increase, if the losses can be neglected.

The contrary case, where the wave is slowed down during the pulse so that the pulse is stretched in time and reduced in frequency, is also of interest. In principle this would permit millimetre waves to be converted to a more easily detected frequency. There effects are large if the switching time of the bias voltage is of the order of the time taken by a wave to pass along the transmission line, which imposes some technical limitations.

However, the chief difficulty at present is in the ferroelectric material. Measurements at $10-\mathrm{cm}$. wavelength of permittivity variation with bias have shown that the effect is still appreciable in a barium-strontium titanate ceramic ${ }^{3}$. Measurements at 3-cm. wavelength showed that relative permittivities of several thousand are still obtained4. There appears to be no published work on these materials at higher frequencies and with d.c. bias applied.

I hope to make some measurements along the lines indicated in this communication at shorter wavelengths than $3 \mathrm{~cm}$. As I have no facilities at present for material manufacture, these measurements will be initially with barium-strontium titanate supplied by an industrial research laboratory. I would be inter. ested to hear from any organization producing titanates or the newer ferroelectric materials which would care to collaborate in a programme of millimetre wave measurements.

D. WALSH

\section{Engineering Laboratory,}

University of Oxford.

${ }^{1}$ Landauer, R., Proc. Inst. Rad. Eng., 48, 1328 (1960).

${ }^{2}$ Landauer, R., IBM J., 4, 391 (1960).

'Davis, I., and Rubin, L. G., J. App. Phys., 24, 1194 (1953).

4Powles, J. G., and Jackson, W., Proc. Inst. Elec. Eng., III, 86, 383 (1949).

\section{GEOLOGY}

\section{Carbonatitic Lava from Fort Portal Area in Western Uganda}

IN an excellent paper Holmes ${ }^{1}$ quotes chemical analyses of two spectacular carbonated lavas, one from the Katwe region, the other from Kalyango volcano near Fort Portal. In earlier work, Holmes and Harwood ${ }^{2}$ described a similar carbonated lava from Lake Kyekora, also near Fort Portal. Present examination of a vesicular lava of high carbonate content poured out from Kalyango volcano shows close geochemical affinities with intrusive carbonatites. It must be emphasized that the lavas examined are fresh and unaltered and that the carbonated nature cannot be attributed to alteration after solidification. A proposed investigation of the numerous lavas in the Fort Portal field may elucidate the formation not only of the characteristic ultrabasic potassic volcanics of south-west Uganda and adjoining parts of the Congo, the petrogenesis of which Holmes has presented so admirably, but also the genesis of the carbonatites themselves.

The field relationships of the Kalyango and other similar 'carbonated' lavas have been described by Combe $^{3}$. Extrusive equivalents of carbonatites are rare, one other occurrence being from Kerimasi volcano in Tanganyika 4 .

A mineralogical, chemical and spectrographic investigation of the lava from Kalyango voleano shows the following characteristics: The rock is lightgrey in colour, variably vesicular with phenocrysts of biotite up to $1 \mathrm{~cm}$. across. It contains frequent inclusions of basement rocks and occasional rounded, possibly eclogitic fragments consisting of a dark-green clinopyroxene and pink garnet. The dense groundmass is powdered with magnetite and the vesicles are lined with a crust of small crystals of calcite and are often filled with spherules and rosettes of fibrous 